\title{
Day Case Haemorrhoidectomy under Local Anaesthesia and Conscious Sedation
}

\author{
Jonathan C. B. Dakubo ${ }^{*}$, Antoinette A. Bediako-Bowan'1, Josephine Nsaful1, \\ Anastasia Ampofo' ${ }^{2}$ \\ ${ }^{1}$ Department of Surgery, School of Medicine and Dentistry, University of Ghana, Accra, Ghana \\ ${ }^{2}$ Department of Obstetrics and Gynaecology, Korle-Bu Teaching Hospital, Accra, Ghana \\ Email: ${ }^{*}$ jdakubo@yahoo.com
}

Received 22 April 2015; accepted 8 June 2015; published 12 June 2015

Copyright (C 2015 by authors and Scientific Research Publishing Inc.

This work is licensed under the Creative Commons Attribution International License (CC BY). http://creativecommons.org/licenses/by/4.0/

(c) (i) Open Access

\begin{abstract}
Background: Excisional haemorrhoidectomy engenders considerable pain and has popularly been managed as an in-patient procedure. There has been anxiety over a major complication occurring in the community instead of in the hospital which is still pervasive in the developing world despite evidence to the contrary. Aim: It compared the post operative complications, time to bowel action, and post-operative pain scores in patients who had open haemorrhoidectomy either under spinal anaesthesia as in-patient or under local anaesthesia as day case procedure. Materials and Methods: The study involved two populations of patients who underwent open haemorrhoidectomy either under spinal anesthesia or under local anaesthesia with conscious sedation at the Korle Bu Teaching Hospital between 2008 and 2013. Results: It involved 275 patients made up of 145 and 130 in the spinal and local aneasthesia groups respectively. Their mean age was 43.1, SD \pm 13.2 and median 41 years. Complications occurred in 44 patients (16\%), 24 and 20 in the spinal and local aneasthesia groups respectively, with bleeding being the most frequent $[11 / 44,(25 \%)]$ and significant. More wound bleeding occurred in the spinal than the local anaesthesia group, 7 vs. 2 patients. Except one day only $(p=0.0001)$ the mean pain scores on days $2,3,5$ and 7 were statistically significantly lower in the spinal group than in the local group. The median time to bowel motion was 4 days in both groups. Conclusion: The post operative outcomes in the two populations were similar except the more frequent bleeding noted in the spinal anaesthesia group. Day case haemorrhoidectomy is safe in centres where day case surgery is routinely performed.
\end{abstract}

\section{Keywords}

Post-Operative Pain, Piles, Anaesthesia Technique, Milligan-Morgan Haemorrhoidectomy, Ambulatory Surgery

\footnotetext{
${ }^{*}$ Corresponding author.
}

How to cite this paper: Dakubo, J.C.B., Bediako-Bowan, A.A., Nsaful, J. and Ampofo, A. (2015) Day Case Haemorrhoidectomy under Local Anaesthesia and Conscious Sedation. International Journal of Clinical Medicine, 6, 392-398. 


\section{Introduction}

Numerous surgical and non-surgical approaches to treat haemorrhoidal disease have been described, each with its benefits and shortcomings. Open excisional haemorrhoidectomy by the Milligan-Morgan method still remains the most effective, considered by some as the "gold standard", because it enables identification of vital structures of the anal canal thereby avoiding their injury [1] [2]. It remains the most popular surgical technique in treating symptomatic hemorrhoids [3] [4].

Open haemorrhoidectomy is attended by significant pain that lengthens hospital stay. The pain results from: incarceration of smooth muscle fibres and mucosa in the transfixed pedicel, bearing the anal canal of its mucosa, spasm of the internal anal sphincter and exposure of pain nerve ending in the peri-anal skin [3] [5]. The amount of pain experienced is related to such factors as the patients' own pain tolerance threshold, surgical technique, type and quality of anaesthesia, effectiveness of postoperative analgesia and bowel movement [1] [5].

The plethora of surgical, anaesthetic, analgesic and other supportive methods that have been tried in addressing these basic problems underlying the genesis of post-haemorrhoidectomy pain gives evidence to the intricacy of this pain. Stapled haemorrhoidopexy and haemorrhoidal artery ligation are the only approaches that currently boast of significant pain reduction and early return to normal activity [6] [7]. A contemporary review of available evidence recommends local anaesthetic infiltration, either as a sole technique or as an adjunct to general or regional anaesthesia, and combinations of analgesics (non-steroidal anti-inflammatory drugs, paracetamol and opiates) for dealing effectively with pain after open haemorrhoidectomy [8].

Day care haemorrhoidectomy has been practiced for many decades in settings where day care surgical systems are established with effectively regulated primary physician services and home-based nursing care, and with links for easy referrals to tertiary health centres [9] [10]. Patient safety is thereby guaranteed.

In the Korle Bu Teaching Hospital (KBTH) the Milligan-Morgan haemorrhoidectomy is the technique used in surgical excision of symptomatic haemorrhoids and is routinely done under either general or spinal anaesthesia (SA) as an in-patient procedure. After the surgery the patients are admitted till they have moved their bowel at least once and when in the judgement of the attending physician there is no risk of significant complication before discharge. This stems from concerns that patient care may be compromised from inadequate analgesia leading to such significant complications as faecal impaction, urinary retention and reactionary haemorrhage occurring in the community rather than the hospital setting if patients are treated as day cases. Justification for this is born from the poor referral systems and the unregulated and ineffective links between community health care facilities and the major hospitals in Ghana.

Since 2004 one general surgery unit at the KBTH has adopted the method of performing open haemorrhoidectomy under peri-anal infiltration of a local anaesthetic and discharging the patients within 24 hrs of admission. A comparative study of patients who underwent haemorrhoidectomy under SA as in-patient procedure in the other three general surgery units and those done under local anaesthesia (LA) with conscious sedation as day case procedure was undertaken to evaluate the treatment outcomes in the two groups, specifically examining the daily pain scores, time to passing the first stool after surgery and post operative complications, and testing the null hypothesis that there are no significant differences between the two groups of patients in terms of postoperative complication rates, daily pain scores, and time to first bowel motion. The outcome of this study is to provide evidence that discharging patients the same day after open haemorrhoidectomy under LA is not associated with abnormally high complication rate and to encourage this practice in order to free hospital beds for more sick patients.

\section{Material and Methods}

This is a comparative study of two populations of patients who underwent open heamorrhoidectomy under either SA as in-patient procedure or peri-anal LA infiltration with conscious sedation as day case procedure. Haemorrhoidectomy is popularly performed under spinal or general anaesthesia at the KBTH. From 2004 one out of the four general surgery units in the Department of Surgery adopted performing the Milligan-Morgan haemorrhoidectomy under LA with conscious sedation and discharging the patients the same day. A study was designed to evaluate the outcomes of this group and those who underwent the same procedure under SP as in-patient procedure.

Patients in the LA group were recruited into the study from January 2008 to December 2013 whilst those in the SA group were recruited from January 2008 to December 2011 and included consenting patients from the 
other three units of the general surgery unit. The time span difference was necessary to enable equivalent numbers of cases to be recruited into each arm of the study.

Three surgeons, made up of one consultant and two senior residents (senior registrars), performed the day case surgeries. Six other consultant surgeons and nine senior residents working in the other three units of the general surgery unit performed the surgeries under SA.

Post operative pain and complications were assessed and recorded daily by personnel trained (Staff Nurses) for this study. Two groups of these personnel assessed the pain during the study, one for each arm of the study. In the LA group the personnel called the patients on phone the day after surgery and daily for a week. The patients in the SA group were visited by the personnel to score the pain daily and resorted to phone calls if they were discharged before the seventh day. Out-patient follow up was arranged for 2 and 4 weeks. The numerical pain score was used, with zero being no pain and 10 the worse pain.

The data collected included: age and sex of the patient, the duration of the symptoms, stage of haemorrhoidal disease, transfusions given, haemoglobin level on admission, time to first bowel motion after the surgery, duration of admission and pain scores for the first seven days after the surgery.

All data was entered into an excel spread sheet and exported to IBM SPSS version 19, New York, for analysis. Frequencies, mean and median were computed and the t-test used to compare means of independent variables. The level of significance was set at 0.05 .

\subsection{Treatment Regimen}

\subsubsection{Spinal Anaesthesia (SA) Group}

A standard spinal anaesthesia, given with the patient sitting, was given following which the haemorroidectomy was done. IV metronidazole $500 \mathrm{mg}$ and Ciprofloxacin $200 \mathrm{mg}$ were given before the surgery and continued 8 hourly and 12 hourly respectively for 48 hrs after the surgery. This was followed with oral metronidazole 400 mg three times daily for 7 - 10 days and oral Ciprofloxacin $500 \mathrm{mg}$ twice daily for 7 - 10 days. The patients received IV fluids for 24 hours and graduated from liquid to normal diet thereafter. IM pethidine 75 - $100 \mathrm{mg} 6$ hourly for between 24 - 48 hrs and then oral diclofenac $75 \mathrm{mg}$ twice daily for 7 - 10 days or tramadol $50 \mathrm{mg}$ three times daily for 7 - 10 days and oral acetaminophen $1 \mathrm{~g}$ eight hourly for up to seven days was the analgesic regime given.

\subsubsection{Local Anaesthesia (LA) Group}

The patients were made to empty their urinary bladder just before the surgery and received only $500 \mathrm{ml}$ of normal saline during the surgery. Intravenous $30 \mathrm{mg}$ pethidine and 2 - $3 \mathrm{mg}$ midazolam were given to sedate the patient permitting undisturbed infiltration of the peri-anal area. The blood pressure, pulse rate, respiratory rate and $\mathrm{SpO}_{2}$ were monitored during and after the surgery in the recovery ward till the patient was fully recovered and transferred to the general ward.

The local anaesthetic solution was made up of $40 \mathrm{ml}$ of $1 \%$ lidocaine with 1:200,000 adrenaline (0.01 mg) and $10 \mathrm{ml}$ of $0.5 \%$ plain bupivacaine. With the patient in the prone jack-knife position the anaesthetic solution was infiltrated through four injection points: two lateral (on each side of the anus), one each anterior and posterior, and fanning out the needle until the entire peri-anal region was anaesthetised. $10 \mathrm{ml}$ of the local anaesthetic was injected into each site inserting the needle deep enough to reach the external anal sphincter which when anaesthetised relaxes and permits easy surgery. Intravenous $500 \mathrm{mg}$ metronidazole and $200 \mathrm{mg}$ Ciprofloxacin were given during the surgery and followed with oral metronidazole $400 \mathrm{mg}$ three times daily and oral Ciprofloxacin $500 \mathrm{mg}$ twice daily for 7 days. Each patient received $100 \mathrm{mg}$ diclofenac suppository at the end of surgery before dressing was applied.

At the end of the surgery the patients were given $70 \mathrm{mg}$ pethidine intramuscularly and at most two more doses of 75 - $100 \mathrm{mg}$ IM pethidine at 6 - $8 \mathrm{hr}$ intervals. They were discharged home by the attending physician after an assessment justified the discharge with specific instructions to return to the hospital and a phone number to call when necessary. Each patient was discharged on oral diclofenac $75 \mathrm{mg}$ twice daily, oral acetaminophen $1 \mathrm{~g}$ three times daily.

\section{Results}

Two hundred and seventy five patients were studied, 145 in the SA group and 130 in the LA group. The overall 
mean age was 43.1, SD \pm 13.2 and median 41 years. Table 1 describes the demographic and clinical parameters of the two groups of patients studied. It shows that the two groups were comparable in: age, $p=0.201$, symptom duration, $p=0.829$, registration haemoglobin levels, $p=0.376$, stage of the haemorrhoids, $p=0.088$ and transfusion requirement, $p=0.451$. The proportions of females in both groups were comparable, $p=0.51$. There was statistically significantly more males in the SA group, 125 , than in the LA group, 109, $\mathrm{p}=0.009$.

Statistically significant but not clinically so was the mean time to bowel motion which was shorter in the local group, 4.15 days, than the spinal group, 4.53 days, $p=0.043$, Table 2 . The patients in the local anesthesia group were discharged from the hospital at a mean time of 12 hrs while that for spinal anesthesia was six days.

The mean pain score was significantly lower in the LA group than in the SA group on day one only, $\mathrm{p}=$ 0.0001 . Statistically however, in the subsequent days, specifically on days $2,3,5$ and 7 , the pain scores were significantly lower in the spinal group than in the local group. There was no difference in pain scores between the two groups on day 4 which was the median day of bowel motion in both groups, Table 3 .

\begin{tabular}{|c|c|c|c|c|c|}
\hline \multirow[b]{2}{*}{ Variables } & \multirow[b]{2}{*}{ Spinal (145) } & \multirow[b]{2}{*}{ Local (130) } & \multicolumn{3}{|c|}{ T-test for independent variables } \\
\hline & & & $\mathrm{t}$ & Sig (2-Tailed) & $95 \% \mathrm{CI}$ \\
\hline Age (years) & & & -1.282 & 0.201 & $-5.187-1.096$ \\
\hline Mean & 42.19 & 44.24 & & & \\
\hline SD & 12.995 & 13.448 & & & \\
\hline Median & 39 & 43.5 & & & \\
\hline IQR & $33-51$ & $33.75-53.25$ & & & \\
\hline \multicolumn{6}{|l|}{ Sex } \\
\hline Male & 125 & 109 & 70.833 & 0.009 & $69.753-100.247$ \\
\hline Female & 20 & 21 & 12.5 & 0.51 & $-0.247-30.247$ \\
\hline Symptoms duration (days) & & & 0.316 & 0.829 & $-12.490-5.549$ \\
\hline Mean & 58.53 & 57 & & & \\
\hline SD & 61.674 & 55.725 & & & \\
\hline Median & 36 & 36 & & & \\
\hline IQR & $12-78$ & $24-72$ & & & \\
\hline Transfusion & & & 0.755 & 0.451 & $-0.219-0.492$ \\
\hline No of patients & 30 & 43 & & & \\
\hline Total units transfused & 149 & 111 & & & \\
\hline Mean transfusion rate & 4.9 & 2.5 & & & \\
\hline Stage of haemorrhoids & & & 1.714 & 0.088 & $-0.025-0.358$ \\
\hline 1 & 10 & 11 & & & \\
\hline 2 & 81 & 77 & & & \\
\hline 3 & 27 & 37 & & & \\
\hline 4 & 27 & 8 & & & \\
\hline Reporting Hb (g/dl) & & & -8.887 & 0.376 & $-1.5413-0.5837$ \\
\hline Mean & 10.01 & 10.489 & & & \\
\hline SD & 4.54 & 4.369 & & & \\
\hline Median & 11.5 & 12.1 & & & \\
\hline IQR & $5.62-13.6$ & $6.5-13.725$ & & & \\
\hline
\end{tabular}


Table 2. Time to bowel motion and duration of admission.

\begin{tabular}{cccccc}
\hline & & & \multicolumn{3}{c}{ T-test for independent variables } \\
\hline Variables & Spinal & Local & $\mathrm{t}$ & Sig (2-tailed) & $95 \%$ CI \\
\hline Time to bowel action (days) & & & 2.031 & 0.043 & $0.012-0.765$ \\
Mean & 4.53 & 4.15 & & & \\
SD & 1.362 & 1.792 & & & \\
Median & 4 & 4 & & & \\
IQR & $3-5$ & $3-5$ & & & \\
Mean & & & & & \\
SD & 151.52 & 12.088 & & & \\
Median & 53.179 & 3.2329 & & & \\
IQR & 144 & 12 & & & \\
\hline
\end{tabular}

Table 3. Pain scores on days one to seven.

\begin{tabular}{|c|c|c|c|c|c|}
\hline \multirow[b]{2}{*}{ Variables } & \multirow[b]{2}{*}{ Spinal } & \multirow[b]{2}{*}{ Local } & \multicolumn{3}{|c|}{ T-test for independent variables } \\
\hline & & & $\mathrm{t}$ & Sig (2-tailed) & $95 \%$ CI \\
\hline Day 1 & & & 12.823 & 0.0001 & $1.862-3.538$ \\
\hline Mean & 3.93 & 1.73 & & & \\
\hline SD & 1.773 & 0.83 & & & \\
\hline Median & 4 & 1 & & & \\
\hline IQR & $3-5$ & $1-2$ & & & \\
\hline Day 2 & & & -4.546 & 0.0001 & $-1.116-(-0.441)$ \\
\hline Mean & 2.51 & 3.29 & & & \\
\hline SD & 0.989 & 1.772 & & & \\
\hline Median & 3 & 3 & & & \\
\hline IQR & $2-3$ & $2-4$ & & & \\
\hline Day 3 & & & -3.09 & 0.002 & $-1.186-(-0.265)$ \\
\hline Mean & 3.15 & 3.88 & & & \\
\hline SD & 1.479 & 2.356 & & & \\
\hline Median & 3 & 3 & & & \\
\hline IQR & $2-4$ & $2-4$ & & & \\
\hline Day 4 & & & -0.817 & 0.414 & $-0.423-0.175$ \\
\hline Mean & 2.15 & 2.28 & & & \\
\hline $\mathrm{SD}$ & 1.118 & 1.39 & & & \\
\hline Median & 2 & 3 & & & \\
\hline IQR & $1-2$ & $2-6$ & & & \\
\hline Day 5 & & & -2.912 & 0.004 & $-0.717-(-0.139)$ \\
\hline Mean & 1.97 & 2.4 & & & \\
\hline SD & 0.877 & 1.502 & & & \\
\hline Median & 2 & 2 & & & \\
\hline IQR & $1-2$ & $1.75-3$ & & & \\
\hline Day 6 & & & 0.539 & 0.59 & $-0.166-0.291$ \\
\hline Mean & 1.85 & 1.75 & & & \\
\hline SD & 1.006 & 0.906 & & & \\
\hline Median & 2 & 2 & & & \\
\hline IQR & $1-2$ & $1-2$ & & & \\
\hline Day 7 & & & -3.533 & 0.0001 & $-1.004-(-0.286)$ \\
\hline Mean & 1.92 & 2.56 & & & \\
\hline SD & 1.034 & 1.901 & & & \\
\hline Median & 2 & 2 & & & \\
\hline IQR & $1-2$ & $1-4$ & & & \\
\hline
\end{tabular}


Overall, complications occurred in 44 patients (16\%), 24 in the SA group and 20 in the LA group, but significant complications requiring admission occurred in 14 (5\%) patients. The complications included 16 cases of urinary retention (SA 11, LA 5), 14 cases of constipation (SA 4, LA 10), 9 cases of bleeds from the wound (SA 7, LA 2), 3 cases of anal stenosis (SA 2, LA 1) and 2 cases of upper gastrointestinal bleed from duodenal peptic ulcer in the LA group. The patients who bleed from their wounds and peptic ulcer and those with anal stenosis required readmission and treatment.

\section{Discussion}

Day care haemorrhoidectomy is an accepted procedure performed in a day care surgical suit in settings with organized and regulated home-based care and links between primary care physician and hospital services [9] [10]. Day case surgical patients are cared for at home and transferred to the hospital urgently when significant complication develops. With such an established quality assurance health delivery system patient safety is guaranteed.

Day case surgery has been performed at KBTH for close to two decades now for minor surgical conditions such as inguinal hernia, hydrocele, varicocele, breast lumps, etc, in the absence of an established day care suit. Patients have open access to the hospital in the event of an emergency and with the instructions given to the patients during discharge the practice has largely been safe. But for the debilitating post-operative pain haemorrhoidectomy is tactically a minor surgical procedure amenable to day care. The hesitation in accepting day case haemorrhoidectomy as a standard of care in the health delivery systems in many developing nations stems from the lack of evidence on the safety of this procedure in a setting where there is virtually no home-based health care service and also with ineffective and unregulated links between primary health care and secondary or tertiary care centres. A recent report from Nigeria on 22 patients who were selected for day case open haemorrhoidectomy shows how feasible this practice can be in the developing world despite these challenges [11]. This comparative study provides stronger evidence on the safety of day case haemorrhoidectomy within the health delivery system of the developing world in centres where other day case procedures are already being done.

Significant complications requiring emergency re-admission and treatment were recorded in 11 patients in this study, 9 cases of both reactionary and secondary haemorrhage and two cases of peptic ulcer bleeding, with many of these cases recorded in the SA group. The two cases of upper gastrointestinal bleeding were from activation of duodenal peptic ulcer from the inadvertent administration of diclofenac to these patients who gave a negative peptic ulcer history before the drug was prescribed to them. The vasodilatation associated with SA can create a bloody field that compromises the quality of haemorrhoidectomy [12]. Infiltration of adrenaline based local anaesthetic agent creates a bloodless field and with the oedema makes dissection easy, with clear identification of structures in the anal canal, the quality of haemorrhoidectomy is improved and this could account for the marked difference in the incidence of haemorrhage between the two groups.

Populations in developing countries are growing faster than the rate at which infrastructure is provided leading to overcrowding in hospitals. Measures to reduce hospital admissions are necessary and one such is to limit admissions as much as possible. Besides the relatively high cost of in-patient haemorrhoidectomy under SA are the risks of cardiac arrest, seizures, neurological complications, headaches and infection of the central nervous system [12] [13]-[15]. Local anaesthesia for haemorrhoidectomy has advantages including ease of dissection from the tissue oedema created, operating a in a bloodless field and low overall cost of the procedure.

The median time to bowel motion of four days was same for both groups. There was a much better pain control on day one for the LA group but on subsequent days the pain control was better for the SA group. The combinations of both anaesthetic agents and analgesics given to the LA group which gave pain relief for a longer period after the surgery could account for the reduced pain on day one. Additionally the knowledge of being discharged on the same day of the surgery could be both a motivation and prophylactic enhancing the pain control in this group.

The patients in the spinal group experienced less pain on post-operative days 2, 3, 5 and 7; the reason for this is not clear given that besides the differences in the anaesthetic technique and intra-operative pain control, all subsequent care was the same for the two groups. Even though there were statistically significant differences among the groups these were not of clinical relevance.

The newer procedures for treating haemorrhoidal disease that are associated with less pain, especially the stapled haemorrhoidectomy and haemorrhoidal artery ligation, require additional training and attended by significant cost in purchasing the stapler or other devices for the surgery and for a long time will be out of reach for 
many patients in the developing world undergoing haemorrhoidectomy. Excisional haemorrhoidectomy will therefore remain as the main approach for treating these patients and adoption of LA for treating it as day case is the way to go.

\section{Conclusion}

There were clinically no significant differences between the LA and SA groups in terms of time to bowel motion, overall complication rates and pain scores during the first week after surgery, so patients can safely be managed at home after haemorrhoidectomy. Excisional haemorrhoidectomy under local anaesthesia significantly reduces post-operative haemorrhage, as a day case procedure could significantly reduce cost of care. Extended stay of patients in hospital after haemorrhoidectomy is therefore not justified.

\section{References}

[1] Brisinda, G. (2000) How to Treat Haemorrhoids. Prevention Is Best; Haemorrhoidectomy Needs Skilled OperatorsEditorials. BMJ, 321, 582-583. http://dx.doi.org/10.1136/bmj.321.7261.582

[2] MacRae, H.M. and McLeod, R.S. (1995) Comparison of Haemorrhoidal Treatment Modalities. A Meta-Analysis. Diseases of the Colon Rectum, 38, 687-694. http://dx.doi.org/10.1007/BF02048023

[3] Hardy, A., Chan, C.L.H. and Cohen, C.R.G. (2005) The Surgical Management of Haemorrhoids-A Review. Digestive Surgery, 22, 26-33. http://dx.doi.org/10.1159/000085343

[4] Niser, P.J. and Scholefeild, J.H. (2003) Managing Haemorrhoids. BMJ, 327, 847-851. http://dx.doi.org/10.1136/bmj.327.7419.847

[5] Ganio, E., Altomare, D.F., Gabrielli, F., Milito, G. and Canuti, S. (2001) Prospective Randomized Multicentre Trial Comparing Stapled with Open Haemorrhoidectomy. British Journal of Surgery, 88, 669-674. http://dx.doi.org/10.1046/j.0007-1323.2001.01772.x

[6] Morinaga, K., Hacuda, K. and Ikeda, T. (1995) A Novel Therapy for Internal Haemorrhoids: Ligation of the Haemorrhoidal Artery with a New Devised Instrument (Moricon) in Conjunction with Dioppler Flowmeter. The American Journal of Gastroenterology, 90, 610-613.

[7] Corman, M.L., Gravie, S.F., Hager, T., Loudon, M.A., Mascagni, D., Nyström, P.-O., et al. (2003) Stapled Haemorrhoidectomy: A Consensus Position Paper by an International Working Party-Indications, Contraindications and Technique. Colorectal Disease, 5, 304-310. http://dx.doi.org/10.1046/j.1463-1318.2003.00483.x

[8] Joshi, G.P. and Neugebeuer, E.A.M. (2010) Evidence-Based Management of Pain after Haemorrhoidectomy Surgery. British Journal of Surgery, 97, 1155-1168. http://dx.doi.org/10.1002/bjs.7161

[9] Hunt, L., Luck, A.J., Rudkin, G. and Hewett, P.J. (1999) Day-Case Haemorrhoidectomy. British Journal of Surgery, 86, 255-258. http://dx.doi.org/10.1046/j.1365-2168.1999.01024.x

[10] Patel, N. and O’Connor, T. (1996) Suture Haemorrhoidectomy. A Day-Only Alternative. Australian and New Zealand Journal of Surgery, 66, 830-831. http://dx.doi.org/10.1111/j.1445-2197.1996.tb00760.x

[11] Alatise, O.I., Agbakwuru, A.E., Takure, A.O., Adisa, A.O. and Akinkuolie, A.A. (2011) Open Haemorrhoidectomy under Local Anaesthesia for Symptomatic Haemorrhoids: An Experience for Nigeria. Arab Journal of Gastroenterology, 12, 99-102. http://dx.doi.org/10.1016/j.ajg.2011.03.004

[12] Liu, S.S. and McDonald, S.B. (2001) Current Issues in Spinal Anesthesia. Anesthesiology, 94, 888-906. http://dx.doi.org/10.1097/00000542-200105000-00030

[13] Auroy, Y., Narchi, P., Messiah, A., Litt, L., Rouvier, B. and Samii, K. (1997) Serious Complications Related to Regional Anesthesia: Results of a Prospective Survey in France. Anaesthesiology, 87, 479-486. http://dx.doi.org/10.1097/00000542-199709000-00005

[14] Auroy, Y., Benhamou, D., Bargues, L., Ecoffey, C., Falissard, B., Mercier, F., et al. (2002) Major Complications of Regional Anesthesia in France: The SOS Regional Anesthesia Hotline Service Anaesthesiology, 97, 1274-1280. http://dx.doi.org/10.1097/00000542-200211000-00034

[15] Brull, R., McCartney, C., Chan, V. and El-Beheiry, H. (2007) Neurological Complications after Regional Anesthesia: Contemporary Estimates of Risk. Anesthesia \& Analgesia, 104, 965-974. http://dx.doi.org/10.1213/01.ane.0000258740.17193.ec 